\title{
The Different Between the Temperature of the Solar Burst at the Feed Point of the Log Periodic Dipole Antenna (LPDA) and the CALLISTO Spectrometer
}

\author{
Z. S. Hamidi ${ }^{1, *}$, N. N. M. Shariff ${ }^{2}$, C. Monstein ${ }^{3}$ \\ ${ }^{1}$ School of Physics and Material Sciences, Faculty of Sciences, MARA University of Technology, \\ 40450, Shah Alam, Selangor, Malaysia \\ ${ }^{2}$ Academy of Contemporary Islamic Studies (ACIS), MARA University of Technology, \\ 40450, Shah Alam, Selangor, Malaysia \\ ${ }^{3}$ Institute of Astronomy, Wolfgang-Pauli-Strasse 27, Building HIT, Floor J, \\ $\mathrm{CH}-8093$ Zurich, Switzerland \\ *E-mail address: zetysh@salam.uitm.edu.my
}

\begin{abstract}
The article attempts to analyze and compare the temperature of solar radio burst at the (i) feed point and antenna and (ii) at the receiver (CALLISTO spectrometer). The analysis is very important to evaluate the performance for a better observation of solar radio burst. We start our project by developing this antenna with 19 elements of different sizes covers from $45-870 \mathrm{MHz}$. We choose the National Space Agency (PAN), Sg. Lang, Banting, Selangor, Malaysia as our site seems this site has a very minimum of Radio Frequency Interference (RFI). The antenna, then connects to the low noise amplifier and the CALLISTO spectrometer as one complete system. Based on the results, it was found that the temperature of the at the feed point of the antenna and receiver is different up to $3.25 \mathrm{~K}$. The average level burst level above background sky is about $0.41 \mathrm{~dB}$. It was found that the power of solar burst at the feed point of the antenna is equivalent to $2.6 \times 10^{-18} \mathrm{~W}$, but decreases to $2.3 \times 10^{-18} \mathrm{~W}$ when detected by the CALLISTO spectrometer. These results show a better understanding of how does the system operate in terms of the process of analysis of the temperature of solar radio burst.
\end{abstract}

Keywords: CALLISTO; Log Periodic Dipole Antenna (LPDA); temperature; solar radio burst

\section{INTRODUCTION}

It is believed that the temperature of solar radio burst is one the main parameters that very significant to study in details the structure and dynamism of burst during the high activity of the Sun. From the temperature, we can potentially analyze and derive others parameters. In principle, the temperature of the burst will gives a higher value compare quiet Sun. During the observation, the feed point of the antenna will be tested and the connection of the cable from the antenna to the receiver should be contact permanent. The log-periodic dipole antenna (LPDA) is first assembled in 1958 by DuHamel and Dwight Isbell, in the ECE Antenna Laboratory and the prepared by Carrel $[1,2]$. The signal of electromagnetic radiation, in this case, a radio signal can be detected with a special arrangement of conductors. Based on 
principles of physics, the energy characteristics vary considerably below the lower frequency limit of the antenna. This antenna is one of the modest design and the effective detector because it can cover a wide range and practical to construct. The signal detection starts from the feed point of the antenna [3].

In previous work, some evaluation in terms of Radio Frequency Interference (RFI) indication has been done [4]. In this paper, we want to identify the temperature of the solar radio burst at the (i) feed point and antenna and (ii) at the receiver (CALLISTO spectrometer). This process of calibration is one of the basic testing to discover the performance of the antenna. The next section will describe a theory of the parameters of the antenna. Section 3 will highlight the results and analysis and conclude our work at the end of the section. There might be other factors that will affect the performance of LPDA such as interference from other nearest sources.

\section{SOME BASIC PROPERTIES OF THE ANTENNA}

A solar radio spectrometer CALLISTO was installed in February 2012 at the National Space Centre; Selangor, Malaysia. We started by proposing this research in early 2011, through the MARA University of Technology, University of Malaya, and the National University of Malaysia and as universities collaborator [5]. The observation period is within 12 hours [6]. The main reason is due to the extreme climate change and towards to the solar maximum at the beginning of 2013. It is believed that the Earth environment has a close connection with Sun activities [7]. We have successfully obtained a good solar radio burst data associated with solar flares and Coronal Mass Ejections (CMEs) [8-10]. The length of the antenna is 5.45 meters and covers the range from $45-870 \mathrm{MHz}$ with a gain of about $7 \mathrm{dBi}$. In order to minimize the RFI signal, we use a low noise preamplifier between the antenna and receiver [4]. The RG58 cable is a good cable in term of practical enough for outdoor application. In principle, each spectrum data file and the tracking log file stored by the CALLISTO software and tracking software are transferred to the data acquisition server to process and display data and the current tracking status in the Space Weather Monitoring Laboratory (SWML) in real time.

In theory, we can calculate the power that flows through the spherical surface, $S$, of a radius, $r$ which is:

$$
P_{d}=\frac{P}{4 \pi^{2}} W a t t / m^{2}
$$

An isotropic antenna is considered to have a power gain, $G=1$. Hence, if an antenna with a gain $G_{T}$ were located at a point 0 , the power has received at this point should be increased by $G_{T}$. Therefore, the field strength at point $Q$ will also be increased.

$$
E=\frac{\sqrt{30 P_{T} G_{T}}}{R} V / m
$$

where, $P_{T}$ is the transmitter power, $\mathrm{G}_{\mathrm{T}}$ is the antenna gain.

Indirectly, this coefficient is an antenna factor, $A_{F}$ and is being determined by on the frequency or equivalent with $(1 / \lambda)$. 


$$
A_{F}=\frac{E}{V_{L}}=\sqrt{\frac{E^{2}}{V_{L}^{2}}}=\sqrt{A C F}
$$

Equation (1) - (3) is the basic and main parameters of antennas which will provide an idea of how do the antenna performs.

\section{RESULTS AND ANALYSIS}

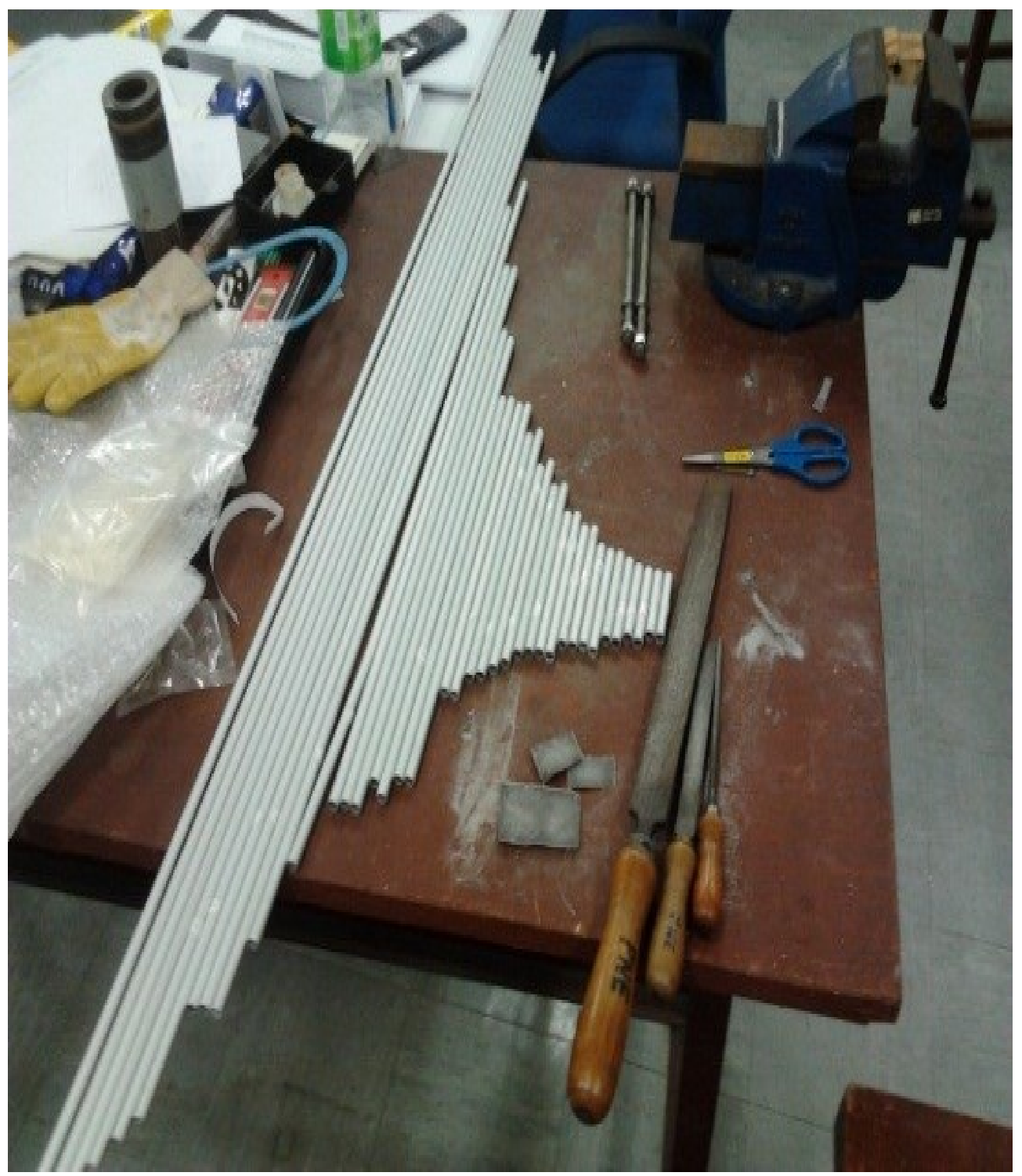

Figure 1. The elements of the antenna at different sizes.

In general, there are many designs and different dimension, but still could possibly give the same specification with the aim of improving its performance or reducing its size. It should be noted that the quality of the antenna also depends on the size of the boom, the type 
of materials of antenna and other mechanical aspects. However, the size of the antenna boom depends on the range of frequency and the longer the size, the better gain can be obtained [11].

In practice, we can estimate the longest half-element which is roughly $1 / 4$ wavelength at the lowest frequency of the bandwidth, while the shortest half-element must be about $1 / 4$ wavelength at the highest frequency in the desired operating bandwidth [12]. We contact the two booms of the antenna by using RG58 [13]. This LPDA antenna contain have 19 elements from aluminium rods [14]. From the previous work, the flux density of the burst is $5.5 \times 10^{-21}$ $\mathrm{W} / \mathrm{m}^{2} / \mathrm{Hz}$ [15]. We also have dome the preliminary analysis of Radio Frequency Interference at MARA University of Technology and at the National Space Centre, Banting, Selangor [16,17]. The elements of the antenna at different sizes are presented in Figure 1.

Still, the mechanism of modification of improving the quality of the LPDA is needed to be done. The antenna is a horizontal orientation and static. One of the suggestion is that by putting a tracking sensor so that the antenna can track as the Sun is rotating from the East to the West. Another solution is by doing interferometry technique and start by two antennas at the same site.

This can provide a better resolution of the image of the burst. This is very important, especially to understand the dynamical structure of solar flares and Coronal Mass Ejections (CMEs) associated with different types of solar bursts [18,19]. For this period, we are focused on the short term variability of solar flare and CMEs events [20]. The data is then can be compared with an X-ray region data [21]. We also successfully analyze a solar radio burst type II due to the CMEs event [22]. There are also other types such as type U, V and IV that have been analyzed in detailed $[23,24]$.

Since our first antenna is operating without a balun, we can start to design a balun of the antenna for the next project. The impact of solar activities indirectly affected the conditions of earth's climate and space weather [25]. It is suggested to design a better cover of the feed point seems the wind in the particular area to be strong. The preparation of construction of the antenna is presented in Figure 2.

In this work, the chosen tau $(\tau)$ and sigma $(\sigma)$ give in the subtended angle of 3.43 degrees while the input impedance, $\mathrm{R}_{0}=50 \Omega$ is chosen for this LPD antenna [8]. In order to make the energy become efficient, the impedance of the antenna and the impedance of the transmission cable connecting them must be the same and matched. Based on theory, the performance of LPDA is a function of the antenna parameters $\tau$ and $\alpha$ [26].

The input impedance will increase toward the value of the unloaded feeder impedance as the value of $\tau$ is decreased. In particular, the input impedance depends on $\tau$ and $\alpha$. In this case, it can be considered as a broadband type with a wide band of $825 \mathrm{MHz}$ within 5.5 meters.

Therefore, the longest dipole in the array will be $3.96 \mathrm{~m}$ long [27]. Overall, the weight of the antenna is about $8.5 \mathrm{~kg}$ and the dimension of the elements will make the antenna not become unstable if too long. Therefore, it is also important to consider a light material of the antenna. The assemble of the antenna is presented in Figure 3. 


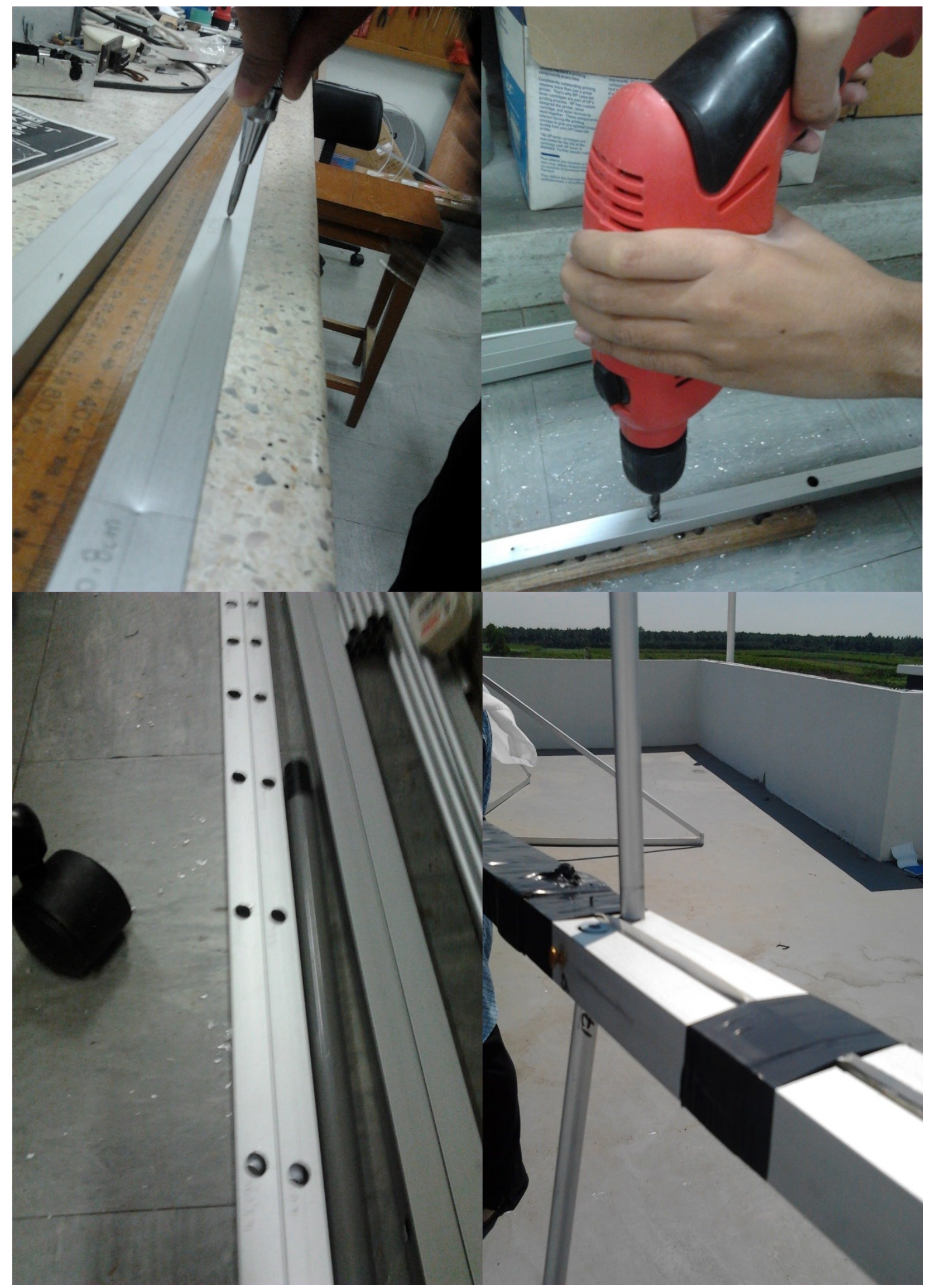

Figure 2. Preparation of construction of LPDA. 


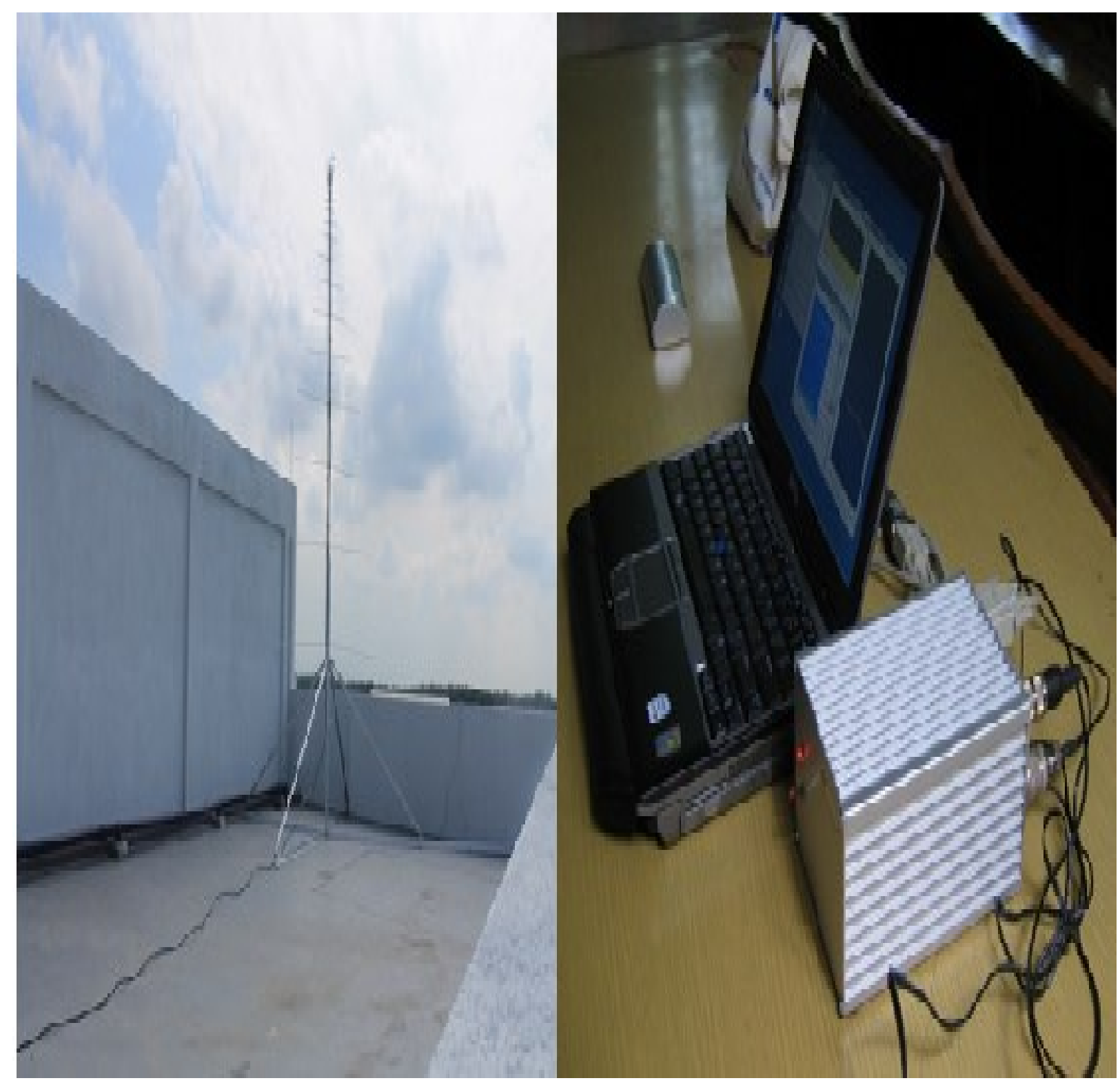

Figure 3. Installation of the LPDA and the CALLISTO system.

\section{RESULTS AND DISCUSSION}

We have examined the antenna by evaluating the temperature of solar radio burst type III. According to the results, it was found that the background sky temperature of the receiver of the antenna is $300.15 \mathrm{~K}$. This makes sense because the temperature during that time is 27 degrees Celsius. Our observation also showed that the burst still can be detected if the temperature of the local site is minimum or less than 30 degrees Celsius. At the feed point at the antenna, the temperature of the burst only is $32 \mathrm{~K}$. Since the temperature of the solar burst at the end of the point of the system should be decreased because of the noise of the cable and other factors, the results of the temperature of solar burst that detected by the CALLISTO system is reduced to $28.75 \mathrm{~K}$. Detailed results of solar burst parameters are illustrated in Figure 4. 


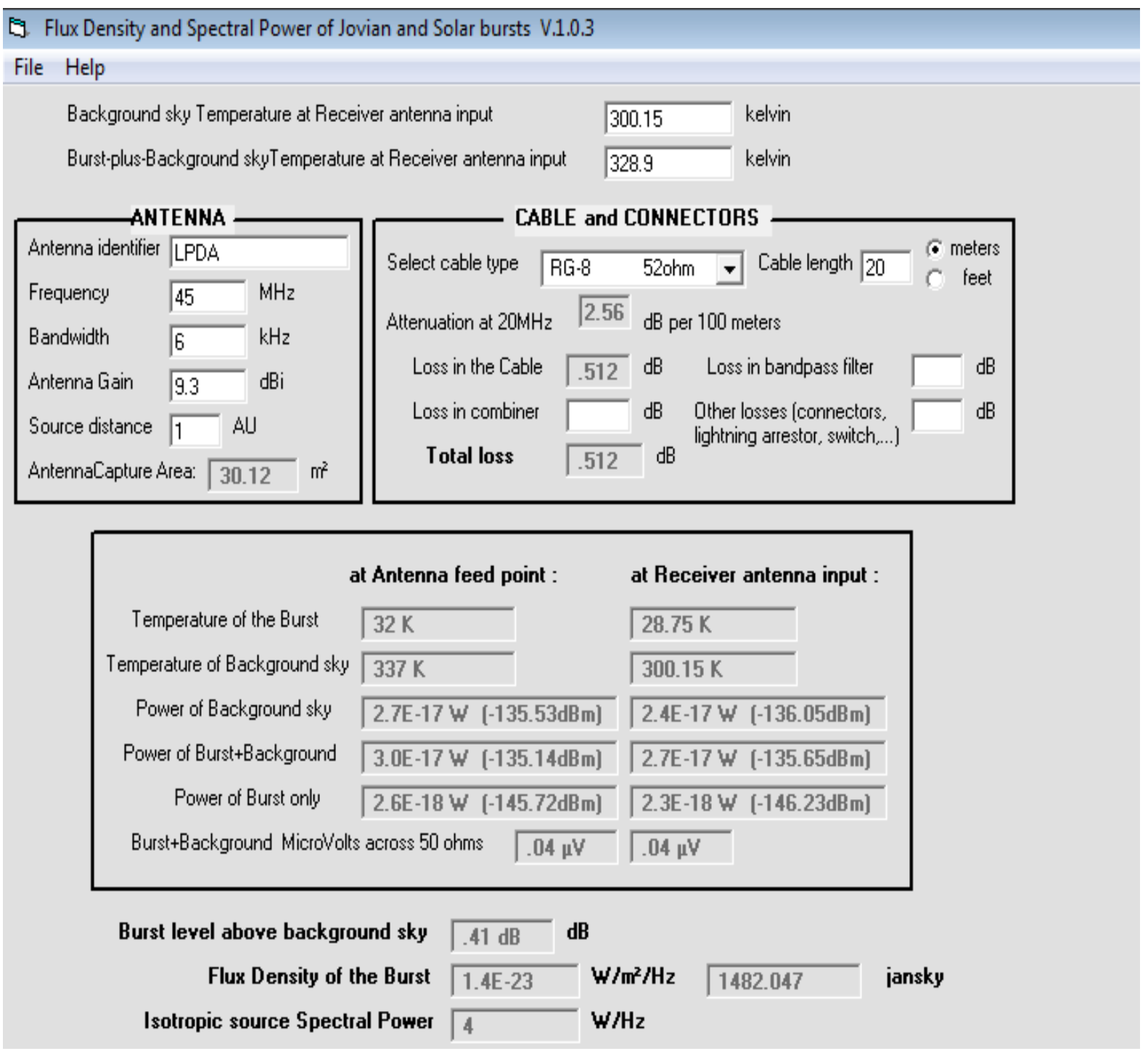

Figure 4. The temperature of solar radio burst at the (i) feed point of antenna and (ii) CALLISTO receiver.

Through the study and research, we found that this antenna potentially captures a signal that covers about $0.08 \mathrm{~m}^{2}$ area of the Sun.

Although the size is considered small, it is still relevant because we are focused on the burst which is generated from the eruption of particles such as electrons, proton and plasma. In this case, the gain of the antenna is $9.3 \mathrm{~dB}$.

Although in theory the value is $10 \mathrm{~dB}$, the actual signal might be less because of the length of the cable. It should be noted that, in terms of length, there is approximately $2.56 \mathrm{~dB}$ of attenuation for every 20 meters. It means that the signal will lose about $0.512 \mathrm{~dB}$ per 100 meters. 


\section{CONCLUSION}

These results show a better understanding of how does the system operate in terms of the process of analysis of the temperature of solar radio burst. But of course, the improvement of the modification of the antenna still needed to be done. Our next task will focus on the other parameters such as the radiation pattern, polarization, operation of the frequency band, gain, input impedance and efficiency of an antenna which indicates the power or field strength radiated in any direction relative to that in the direction of maximum radiation which is also should be considered.

\section{ACKNOWLEDGEMENT}

We are grateful to LASCO,SDO/AIA, NOAA and SWPC make their data available online. This work was partially supported by the FRGS (600 RMI/FRGS 5/3 2012) UiTM grants. Special thanks to the National Space Agency and the National Space Centre for giving us a site to set up this project and support this project. Solar burst monitoring is a project of cooperation between the Institute of Astronomy, ETH Zurich, and FHNW Windisch, Switzerland, MARA University of Technology and University of Malaya. This paper also used NOAA Space Weather Prediction Centre (SWPC) for the sunspot, radio flux and solar flare data for comparison purpose. The research has made use of the National Space Centre Facility and a part of an initiative of the International Space Weather Initiative (ISWI) program.

\section{BIOGRAPHY}

Dr. Zety Sharizat Hamidi is currently a lecturer and focused in Solar Astrophysics research specifically in radio astrophysics at the School of Physics and Material Sciences, Faculty of Sciences, MARA University of Technology, 40450, Shah Alam, Selangor, Malaysia. Involve a project under the International Space Weather Initiative (ISWI) and also a lecturer in School of Physics and Material Science, at MARA University of Technology, Shah Alam Selangor.

Dr. Nur Nafhatun Md Shariff is a senior lecturer in Academy of Contemporary Islamic Studies (ACIS), MARA University of Technology, 40450, Shah Alam, Selangor, MalaysiaHer current research is more on sustainability; environmental aspect. She is looking forward for cross-field research, i.e. solar astrophysics, light pollution measurement (mapping) and religious studies.

C. Monstein is a senior Engineer at Institute of Astronomy, Wolfgang-Pauli-Strasse 27, Building HIT, Floor J, CH-8093 Zurich, Switzerland and one of the researchers who initiated the CALLISTO system around the world.

\section{References}

[1] R.H. DuHamel, D.E. IsBell, Broadband Logarithmically Periodic Antenna Structures, IRE national convention record, 1957, pp. 119-128.

[2] R.L. Carrel, Analysis and Design of the Log-Periodic Dipole Antenna, Elec. Eng. Dept., University of Illinois, 1961.

[3] Z.S.Hamidi, Z. Abidin, Z. Ibrahim, C. Monstein, N. Shariff, International Journal of Fundamental Physical Sciences 2 (2012) 32-34.

[4] Z.S.Hamidi, Z.Z.Abidin, Z.A. Ibrahim, N.N.M. Shariff, Indication of radio frequency interference (RFI) sources for solar burst monitoring in Malaysia, AIP Conference Proceedings 1454 (2012) 43. 
[5] Z.S.Hamidi, N.N.M.Shariff, Z.Z. Abidin, Z.A. Ibrahim, C.Monstein, Malaysian Journal of Science and Technology Studies 9 (2013) 15-22.

[6] Z.S. Hamidi, N. Shariff, Z. Abidin, Z. Ibrahim, C. Monstein, Middle-East Journal of Scientific Research 12 (2012) 6.

[7] Z.S. Hamidi, N.N.M. Shariff, C. Monstein, Z. Abidin, Z. Ibrahim, N. Hashim, R. Umar, N. Aziz, International Journal of Fundamental Physical Sciences 3 (2013) 57-63.

[8] Z.S.Hamidi, N.M.Anim, N. N.S.Hakimi, N.Hamzan, A.Mokhtar, N.Syukri, S.Rohizat, I.Sukma, Z.A. Ibrahim, Z.Z.Abidin, N.N.M.Shariff, C.Monstein, International Journal of Fundamental Physical Sciences 2 (2012) 4.

[9] Z.S.Hamidi, Z. Abidin, Z. Ibrahim, N. Shariff, C. Monstein, Observations of coronal mass ejections (CMEs) at low frequency radio region on 15th April 2012, in: R.Shukor (Ed.), PERFIK 2012, American Institute of Physics, Malaysia, 2013, pp. 5.

[10] Z.S. Hamidi, N. Anim, N.N.M. Shariff, Z.Z. Abidin, Z.A. Ibrahim, C. Monstein, Dynamical structure of solar radio burst type III as evidence of energy of solar flares, in: R.Shukor (Ed.), PERFIK 2012, American Institute of Physics, Malaysia, 2013, pp. 11-15.

[11] Z.S. Hamidi, Z. Ibrahim, Z. Abidin, M. Maulud, N. Radzin, N. Hamzan, N. Anim, N. Shariff, International Journal of Applied Physics and Mathematics 2 (2011) 3.

[12] W.L. Stutzman, G.A. Thiele, Antenna Theory and Design, 2nd ed., John Wiley and Sons, New York, 1998.

[13] R.L. Carrel, The Design of Log-Periodic Dipole Antennas, IRE Int. Conv. Rec., 1961, pp. 61-75.

[14] Z.S.Hamidi, Z. Abidin, Z. Ibrahim, N. Shariff, C. Monstein, International Journal of Engineering Research and Development 3 (2012) 36-39.

[15] Z.S. Hamidi, N.N.M.Shariff, International Letters of Chemistry, Physics and Astronomy 7 (2014) 21-29.

[16] Z.S. Hamidi, Z.Z. Abidin, Z.A. Ibrahim, N.N.M. Shariff, U.F.S.U. Ibrahim, R. Umar, Preliminary analysis of investigation Radio Frequency Interference (RFI) profile analysis at Universiti Teknologi MARA, IEEE, 2011, pp. 311-313.

[17] Z.S. Hamidi, N.N.M.Shariff, C.Monstein, International Letters of Natural Sciences 5 (2014) 10-17.

[18] Z.S. Hamidi, N.N.M. Shariff, Thermal Energy and Power Engineering 3 (2014) 181-184.

[19] Z.S. Hamidi, N.N.M.Shariff, International Letters of Chemistry, Physics and Astronomy 4 (2014) 29-36.

[20] Z.S. Hamidi, N.N.M. Shariff, M.F. Ali, C. Monstein, W.N.A.W. Zulkifli, M.B. Ibrahim, N.S. Arifin, N.A. Amran, International Letters of Chemistry, Physics and Astronomy 9 (2014) 84-92.

[21] Z.S. Hamidi, N.N.M.Shariff, C.Monstein, W.N.A.W. Zulkifli, M.B. Ibrahim, N.S. Arifin, N.A. Amran, International Letters of Chemistry, Physics and Astronomy 8 (2014) 13-19. 
[22] Z.S. Hamidi, N.N.M.Shariff, C.Monstein, W.N.A.W. Zulkifli, M.B. Ibrahim, N.S. Arifin, N.A. Amran, International Letters of Chemistry, Physics and Astronomy 9 (2014) 8-12.

[23] Z.S. Hamidi, N.N.M.Shariff, International Letters of Chemistry, Physics and Astronomy 7 (2014) 30-36.

[24] Z.S. Hamidi, N.N.M.Shariff, International Letters of Chemistry, Physics and Astronomy 5 (2014) 32-42.

[25] Z.S. Hamidi, N.N.M.Shariff, C.Monstein, Z.A. Ibrahim, International Letters of Chemistry, Physics and Astronomy 7 (2014) 37-44.

[26] C.E. Smith, Log Periodic Antenna Design Handbook, 1st ed., Ohio, 1966.

[27] Z.S.Hamidi, S. Chumiran, A. Mohamad, N. Shariff, Z. Ibrahim, N. Radzin, N. Hamzan, N. Anim, A. Alias, American Journal of Modern Physics 2 (2013) 4. 